\title{
Preventive Maintenance and Fault Diagnosis of Pump Motor Bearings
}

\author{
S.Srinivasa Rao ${ }^{1}$, Varre Chaitanya Vikas ${ }^{2}$, Malla Raghava Rao ${ }^{3}$ \\ ${ }^{1}$ ASSOCIATE PROFESSOR, ${ }^{2}$ PG Student (Machine Design), ${ }^{3}$ DGM, Technical Services, Vizag Steel Ltd, \\ ${ }_{1 \& 2}$ Department of Mechanical Engineering, MVGR College of Egg, Vizianagaram, Andhra Pradesh
}

\begin{abstract}
Condition based maintenance (CBM) is an effective way to reduce costs and improve availability because it reduces unnecessary maintenance and prevents failures. CBM is effective for critical plant, including that which is of high capital value, production intensive or where a safety issue exists. This section revises maintenance strategies, defines CBM, and reviews planning considerations. Present work deals with an experimental investigation to monitor vibration condition of pump motor bearings (PMB) of large utility in processing plant. Motor is supported by 2 bearings. Tri-axial measurements were made at bearing supports for 4 times in 8 months. Velocity was measured along vertical, horizontal and axial directions. Based on peaks in the spectrum, causes for excessive vibrations were diagnosed. Remedial actions are to be taken to ensure safer operation of total motor and pump unit.
\end{abstract}

Key Words: motor, pump and condition monitoring.

\section{Introduction}

Condition based maintenance (CBM) is a management philosophy that posits repair or replacement decisions on the current or future condition of assets [1-2 and 9], it recognizes that change in condition and/or performance of an asset is the main reason for executing maintenance [6-7]. Since a few decades industry has started to use predictive and proactive maintenance. In the predictive maintenance, one decides on the maintenance intervals by assessing the condition of the asset [5]. This is done through analysis of e.g. vibrations, oil quality, temperature, voltages and currents, acoustics etc. Preventive maintenance is also called Condition Based Maintenance (CBM) [10]. Condition Based Maintenance has been defined as "Maintenance actions based on actual condition (objective evidence of need) obtained from in-situ, non-invasive tests, and operating and condition measurement" [3]. Proactive maintenance is also called Reliability based maintenance and Precision maintenance. In proactive maintenance one tries to find the root cause of a failure and then tries to prevent it from happening again by making changes in construction, operations or production. All maintenance techniques have their positive and negative qualities. Condition based maintenance (CBM) is an effective way to reduce costs and improve availability because it reduces unnecessary maintenance and prevents failures [4]. CBM is effective for critical plant, including that which is of high capital value, production intensive or where a safety issue exists. This section revises maintenance strategies, defines CBM, and reviews planning considerations.

\section{Motor And Pump Unit}

Motor and a centrifugal pump (Fig. 1) with barrel casing design is used to pump water at high pressure to processing plant. The power of the motor is $275 \mathrm{Kw}$. Its capacity is $1340 \mathrm{~m}^{3} / \mathrm{hr}$, head $60 \mathrm{Mwc}$. The suction types of the pump are gate \& butterfly valves each in 2 no's. The delivery type of pump are gate valve in 4 no's. Present work deals with motor shaft supported by 2 bearings which are Non-driving end 1 (i.e. NDE 1) and driving end 2 (i.e.DE 2) bearings of the motor. As per ISO 10816 standards of vibration limits the machine comes under class 3 (Table 1 shown below)

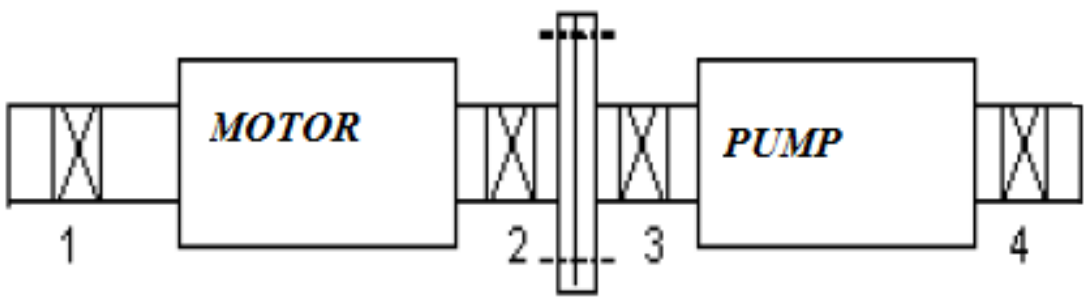

Fig. 1 Line diagram of motor \& pump bearings (1) motor non driving end (MNDE), 2 motor driving end $(M D E), 3$ pump driving end (PDE), 4 pump non driving end (PNDE) 
Preventive Maintenance And Fault Diagnosis Of Pump Motor Bearings

Table 1 vibration limits as per ISO 10816 standards

\begin{tabular}{|c|c|}
\hline Standard vibration level & Machine condition \\
\hline Up to $4.5 \mathrm{~mm} / \mathrm{sec}$ & Normal \\
\hline 4.5 to $11.2 \mathrm{~mm} / \mathrm{sec}$ & Marginal \\
\hline Above $11.2 \mathrm{~mm} / \mathrm{sec}$ & Critical \\
\hline
\end{tabular}

\section{Experimental}

Single channel vibrometer CSI 2117 (frequency $10 \mathrm{~Hz}-30 \mathrm{kHz}$ ) with Dynamic range greater than 70 $\mathrm{dB}$ measured velocity on two month intervals for eight months. Instrument is mounted on 4 bearing supports along vertical (V), horizontal (H), axial (A) directions; all four bearings are in line with axis of the motor shaft.

\section{Results \& Discussion}

Triaxial measurement of velocity is recorded every two months interval at two bearing supports (Tables $2 \& 3$ ). Looking in to velocity history at bearing 1, vibrations are in control until July. During July velocity exceeded the limit (Table 1) [8] in all the three directions. It was observed that from peaks in the spectrum continuously 1xRPM. Fault has been identified as misalignment of bearing. Alignment of bearing reduces velocity intensities. Spectrums as shown below for all the three directions Fig. 2.

Table 2 Triaxial measurement at bearing-1

\begin{tabular}{|c|c|c|c|}
\hline \multirow{2}{*}{ Month } & \multicolumn{3}{|c|}{ Velocity mm/sec } \\
\cline { 2 - 4 } & VERTICAL (V) & HORIZONTAL (H) & AXIAL (A) \\
\hline JANUARY & 6.313 & 5.067 & 8.133 \\
\hline MARCH & 1.753 & 5.144 & 10.47 \\
\hline MAY & 0.917 & 1.087 & 1.660 \\
\hline JULY & 12.60 & 11.69 & 17.61 \\
\hline
\end{tabular}

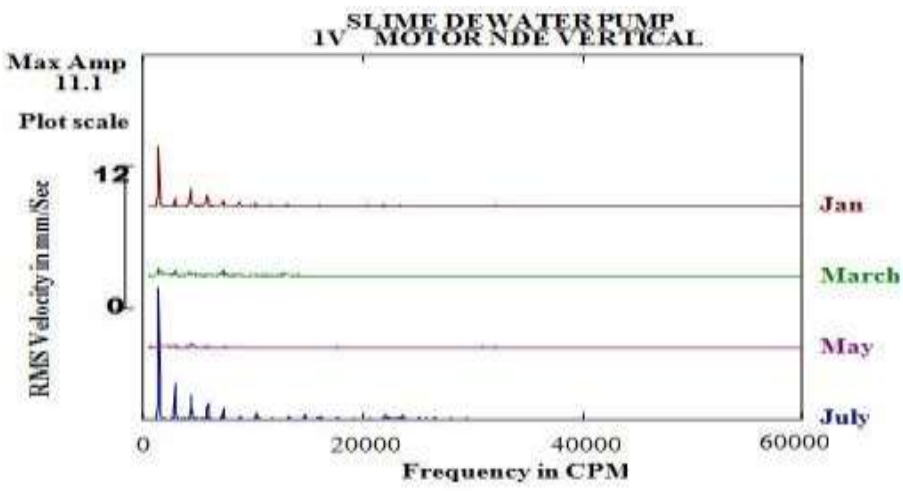

(a)

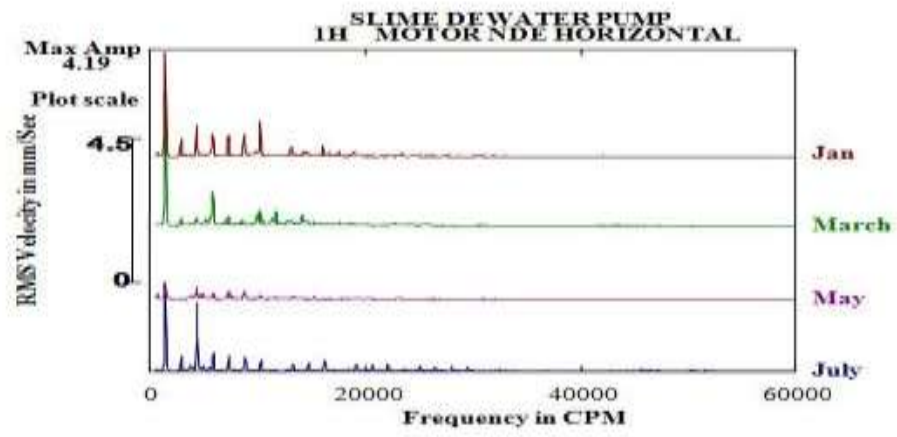

(b) 


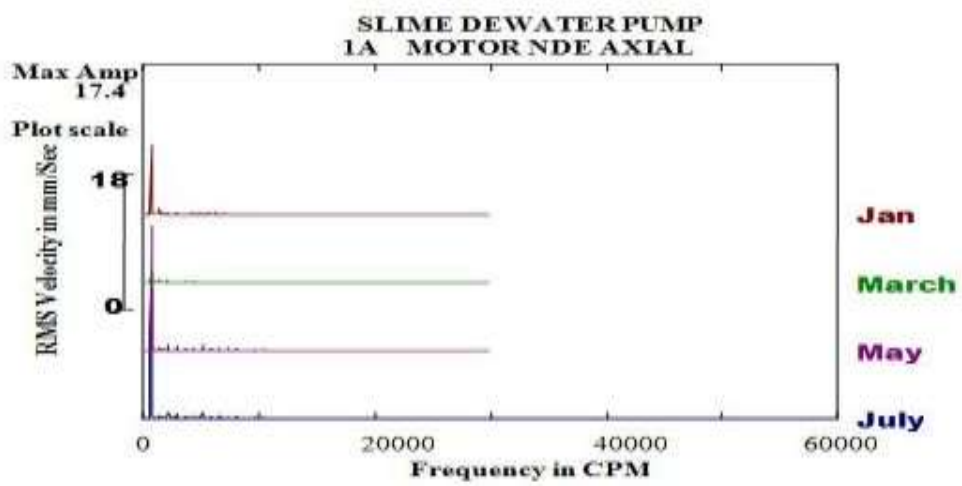

(C)

Fig. 2- spectrums at bearing 1: a) vertical direction b) horizontal direction c) Axial direction

Looking in to velocity history at bearing 2 velocities in all the directions are in marginal limits until January. In the month of March velocities are high in the axial and horizontal directions, whereas vertical direction measurements were well within the limits. Again in the month of May velocities in all the three directions are in the limits. From the velocities in July are high in vertical and axial directions. It was observed that from peaks in the spectrum continuously 1xRPM. Fault has been identified as misalignment of bearing. Alignment of bearing reduces velocity intensities. Spectrums as shown below for all the three directions Fig. 3 .

Table 3 Triaxial measurement at bearing 2

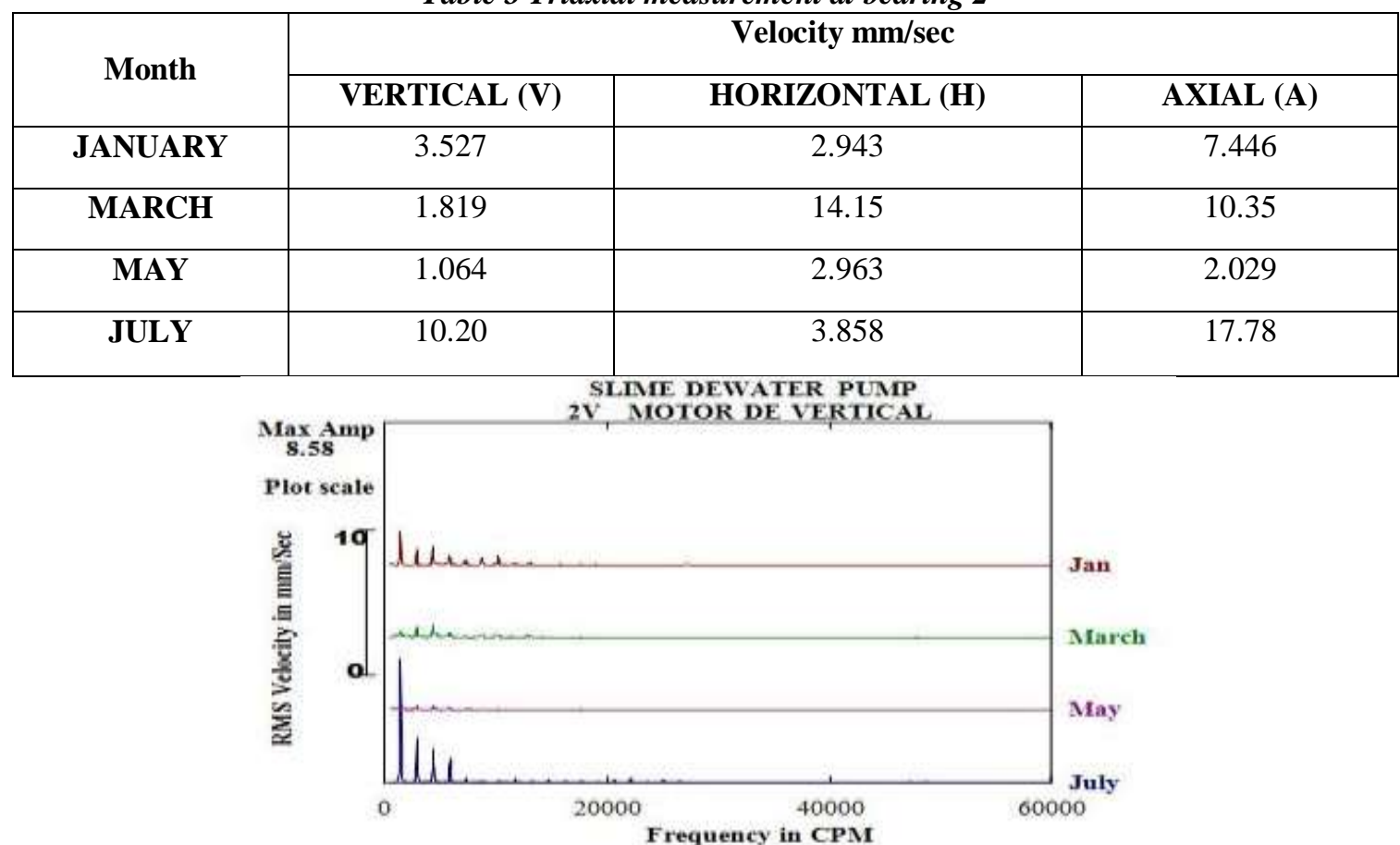

(a)

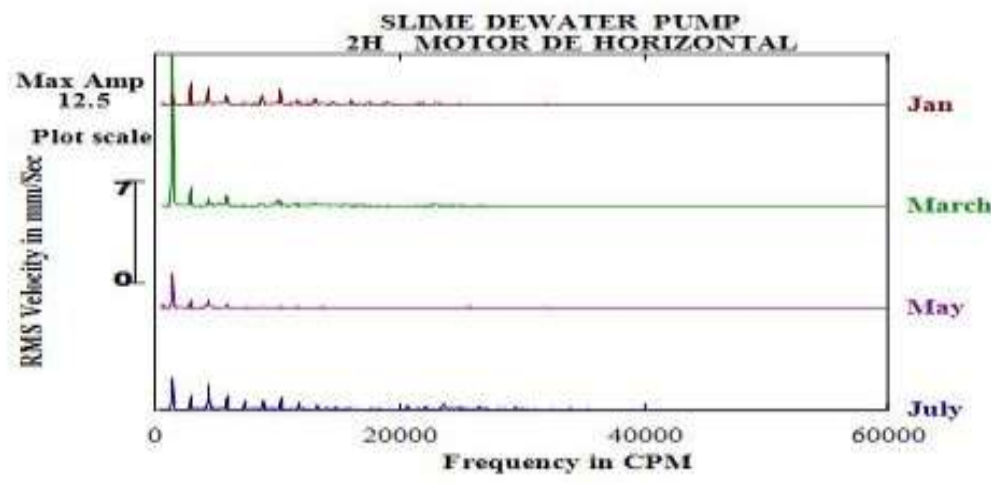

(b) 


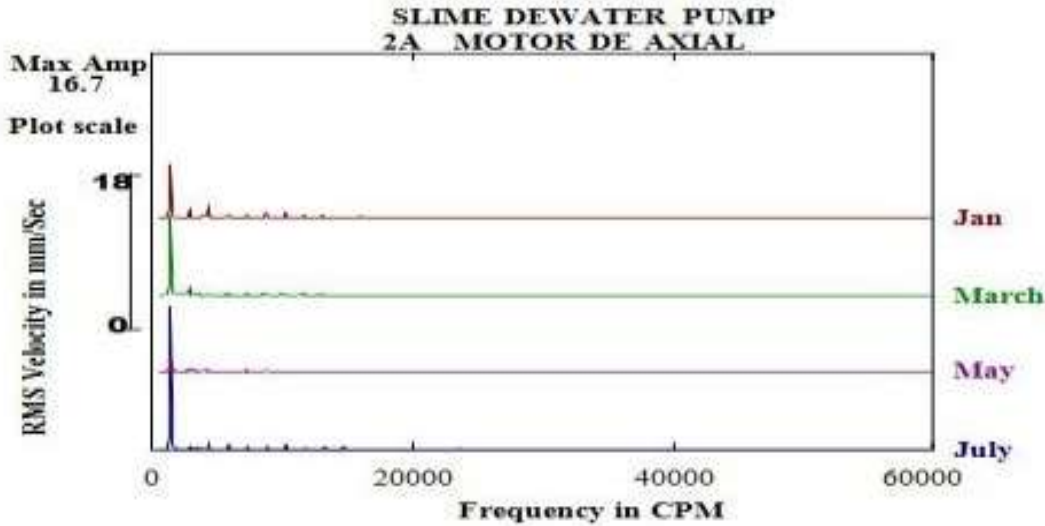

(c)

Fig. 3- spectrums at bearing 2: a) vertical direction b) horizontal direction c) Axial direction

\section{Conclusion}

Condition monitoring for pump of large utility in the processing plant was carried out by vibration measurements to ensure safer operation of the unit. Causes for excessive vibrations at specified locations ( 1 and 2 bearing) were identified in form misalignment and soft foot during periodic monitoring. A remedial action has to be taken for realignment of bearing and replacement of existing footing structure with new one.

\section{References}

[1] Bengtsson, M. Condition Based Maintenance on Rail Vehicles - Possibilities for a more effective maintenance strategy, Technical Report (Mälardalen University), IDPMTR, 2002, 02:06

[2] Bengtsson, M. Standardization Issues in Condition Based Maintenance. COMADEM Conference, Växjö University Press, Sweden, Växjö, 2003.

[3] Butcher, S. W. Assessment of Condition-Based Maintenance in the Department of Defense, LOGISTICS MANAGEMENT INSTITUTE, USA, McLean, VA, 2000, pp. 1-70

[4] Cadick, J. Condition Based Maintenance- How to get started, http://www.cadickcorp.com/download/cbm-howtogetstarted.pdf (2003-10-08)

[5] Evans, J. P., Utilizing Advanced Monitoring \& Diagnostic Technologies to Implement a Condition-Based Maintenance Program

[6] Fenton, B., McGinnity, T.M., Maguire, L.P., Whither AI in Test and Diagnosis, AUTOTESTCON Proceedings, USA, Valley Forge, $P A, 2001$, pp. 333-351.

[7] Horner, R.M.W., El-Haram, M.A., and A.K. Munns. Building maintenance strategy: a new management approach, Journal of Quality in Maintenance Engineering, 1997, Vol. 3 No. 4, pp. 273-280.

[8] ISO 10816 STANDARDS FOR VIBRATION LIMITS

[9] Raheja, D., Llinas, J., Nagi, R. \& Romanowski, C. Data fusion/data mining based on architecture for condition based maintenance. International Journal of Production Research (2006).

[10] Ralph A C, Condition monitoring and fault diagnosis, PROC COMADEM, 1988, 15. 